\title{
17 \\ Advances of Sharing Economy in Agriculture and Tourism Sectors of Albania
}

\section{Eglantina Hysa and Alba Demneri Kruja}

\section{Introduction}

This chapter is looking at the agricultural and tourism sectors in Albania to show how sharing/collaborative economy is gaining ground and what are the potentialities. Additionally, this study aims to look at how stakeholders from the quadruple helix can meaningfully contribute to sharing economy and its' expansion throughout these sectors.

The definition of Wosskow (2014) describing the 'sharing economy' as 'online platforms that help people share access to assets, resources, time and skills' (p. 7), is found to fit with the sharing economy practices in Albania and at the same time how the sharing concept is being

E. Hysa $(\varangle)$

Department of Economics, Epoka University, Tirana, Albania e-mail: ehysa@epoka.edu.al
A. D. Kruja
Department of Business Administration, Epoka University, Tirana, Albania e-mail: akruja@epoka.edu.al 
perceived in this country. Meanwhile, in order to have people that actively use digital platforms, it is important to screen the digitalisation capacities in this country. As such, although a middle-income country, the digitisation process has progressed relatively on similar criteria as with developed countries. Nearly $97.5 \%$ of enterprises have made usage of computers during 2019 for job-related issues (Institute of Statistics 2020a). Meanwhile, $97.8 \%$ of them have internet access, while in the European Union (EU) countries, this ratio is, on average, around 97\%. Albania government has done some concrete steps towards digitalisation and convergence with the EU countries. As such, being in full compliance with the EU Acquis Communautaire, Albania adopted the legal framework of digitalisation. In this line, Albania is having a full understanding and compliance with the Digital Single Market too (Ministry of Innovation and Public Administration 2014). Even though there are many adoptions in this area, still the concept of the term 'collaborative economy' and 'sharing economy' is not well-perceived from the business side, and this awareness is being modest in Albania (Economy Co-Responsibility Learning 2016). There are evidenced implementations of collaborative platforms in sectors such as tourism, agriculture, health, food delivery, and transportation, but still there cannot be found a collaborative economy definition of the country.

Referring to the Timbro Sharing Economy Index (TSEI), Albania is listed 79th out of 213 countries, wherein 2018 scored 3.3 points, considering the highest value of this index to be 100 (TIMBRO 2018). Even though Albania is found in the 2 nd quarter of the list, the sharing index of this country is still below the other Western Balkan Countries (WBC). Montenegro is being at the top of WBC, ranked 4th in the overall list and having the sharing index equal to 58 points. Based on the TIMBRO (2018) database, the rest of the countries are found to be listed as follows: Bosnia and Herzegovina are placed in 64th place (5.7 sharing index), Macedonia is placed in 67 th place (4.7 sharing index), and Serbia is placed in the 71 st place (4.2 sharing index).

Kemp (2020) measures internet penetration in Albania for 2020 as $72 \%$, which is much higher than the worldwide penetration of $59 \%$. A high level of Internet's dissemination and usage is an indication of a high potential of social networks users, as well as a potential for the sharing 
economy further developments as its main infrastructure condition. Yet, the information and communication technology (ICT) industry's contribution is recognised as a policy framework aiming to strengthen the economy and central to the medium- and long-term vision of Albania's development (International Telecommunication Union 2016). A synergic collaboration among the ecosystem stakeholders is crucial for the industries' as well as the economic development of the country (Kruja 2020a). The emergence of collaborative clusters composed of purposive stakeholders from diverse industry areas such as agriculture, tourism, public sector, and others are decisive in sitting side by side the main actors of these industries (International Telecommunication Union 2016). Moreover, the role and support of ICT is determinant, as it is in the centre of interaction with different ICT cluster ecosystems such as agriculture ecosystem, tourism cluster ecosystem, public sector cluster ecosystem, and another cluster ecosystem (International Telecommunication Union 2016).

However, not to be underestimated, these sectors need to have incentives and ongoing processes of entrepreneurial actions. For instance, as one of the essential sectors in Albania, the agriculture sector needs to be pushed by the entrepreneurial spirit to be boosted (Hysa and Mansi 2020). In addition, there are many multi-dimensional contributions of the sharing economy to a country's development, but at the same time, its implementation is combined with many multi-dimensional challenges. Researchers argue that through these collaborative platforms, it is achieved an increase in employment as well as resource usage efficiency (Stahel 2010; Hysa et al. 2020). Another main contribution is the transparency of all the processes, as they are performed online, by reducing corruption and building trust among partners.

Meanwhile, there are some developments in sharing and collaborative economy, Albania as many other countries, still lack legislative regulations on performing necessary sharing economy-related activities and transactions. In terms of specific policies, there were concerns about taxation on ICT firms and start-ups, the role procurement plays in supporting the ecosystem, support for key actors and projects in the ecosystem, and the enforcement of intellectual property rights (ITU 
2016). So legislative regulations are needed for taxation, social security, and health insurance (Hysa et al. 2021). Besides these concerns, Corradini and Re (2016) point out the financial support required for digital investments, which is mostly facilitated by public-private partnerships, along with ICT skilled personnel appropriate for maintaining this continuous development.

To exploit the digitalisation potentiality, bottlenecks need to be removed, and an adequate environment has to be created (Corradini and Re 2016). Hysa et al. (2020) propose the quadruple helix, as a collaboration framework of sustainable innovation, by also integrating the society helix as the main component of consumer awareness. Meanwhile, Tukiainen et al. (2015) introduce the city as an orchestrator for innovation by arguing that 'cities should establish an active dialogue with their citizens, and private and public sectors actors to co-create, develop, test, and offer service innovations that utilise diverse sets of platforms such as living labs' (p. 16). In this study, taking into consideration that Albania is a developing country in need of government policymaking and infrastructure support of sustainable innovation, it is proposed the quadruple helix collaboration framework, in-between and among academia-industrygovernment-society to achieve an effective and efficient collaborative economy.

\section{Sharing Economy Developments in Albania}

Even though the concept of sharing is relatively new to the Albanian market, Albania succeeded to make significant progress in the sharing economy. In this last decade, the usage of sharing platforms was widely used by both public, private, and not for profit entities. Digitalisation, technology advancement and innovation should be the fundamental tools to develop the sharing economy. As such, the Government of Albania developed two strategies supporting innovation and platforms needed for the sharing economy. The first strategy, the National Strategy for Science, Technology, and Innovation (STI) 2009-2015, provisioned the capacity building of public and private entities with special emphasis on STI. The National Strategy for STI is the first strategy of this kind, 
settling a long-term platform of research and innovation development in Albania (Council of Ministers 2009). This strategy was followed by the 'Digital Agenda for Albania 2015-2020,' which presents a crosscutting strategy and serves to strengthen the process of innovation. Concretely, different from the first one, this second strategy aimed to digitalise as much as possible all public institutions. Through this strategy, Albania lined up the embracement of the digital revolution, supporting the creation of new opportunities for citizens and business to benefit (Ministry of Innovation and Public Administration 2014).

In this regard, and in compliance with the first and second strategy, in 2014, the government of Albania launched the governmental platform, a central one, e-Albania. E-Albania offers an extensive list of services that help each and every individual, citizens of Albania or foreigners to download instant official documents. This portal is an important support structure for businesses and public institutions too. The COVID-19 lockdown increased the visibility and usage of this portal. Due to some constraints, citizens were obliged to use the portal, increasing both awareness and usage. At the same time, it is seen that the portal has multiplied its' functions and services, increasing this support to its' users. Apart from governmental incentives to become an 'e-service government,' another important factor in the sharing economy is the municipality of Tirana. Starting with the example of the Chinese bike-sharing giant Mobile in 2018, the municipality of Tirana intends to become a smart city.

With regard to private entities, the sharing economy is introduced by some globally operating firms. At the same time, the Albanian companies have been substantial influencers in adopting the international markets and trends and becoming crucial drivers to innovation in the domestic market. As aforementioned, two main sectors for Albania, agriculture, and tourism, have also been mostly influenced by the collaborative economy. Table 17.1 presents the examples of domestic and global scaled division of sectoral analysis division industries having some examples of sharing (collaborating) economy for the case of Albania. 
Table 17.1 Industry-based examples of the sharing economy in Albania

\begin{tabular}{ll}
\hline Analysed sectors & Selected collaborative examples \\
\hline Agriculture & Agroquality (domestic) \\
Tourism & MIA (domestic) \\
& IntoAlbania (Innovative Tourism in Albania) (domestic) \\
& Innovation Map Albania (domestic) \\
& Team Albanians (domestic) \\
& Softmogul (domestic) \\
\hline
\end{tabular}

Source Own elaboration

\section{Sectorial Developments and Complementary Strengths, Weaknesses, Opportunities, and Threats Analysis}

This session is focussed at the sectorial analysis of agriculture and tourism. These sectors are found to be key sectors for Albania, given its' natural resource endowment and geographic position. Moreover, it can be noticed that the sharing economy is mainly evident in these sectors. This might be because of their swift development and their success in the developments of the same sectors abroad.

\section{Agriculture Sector Endowments}

Agriculture is one of the main critical economic sectors of Albania as it contributes to approximately one-fifth of the country's GDP (Gecaj et al. 2019). The country's geographic positioning, $1 / 3$ of which is wet by the Adriatic and Ionian Seas, enables cultivating agricultural products in a fertile land of coastal areas where is concentrated most of the production of vegetables as well as the cultivation of fruit trees, while in the northern part, chestnut cultivation occupies significant weight, and in mountainous areas, a wide range of medicinal plants and aromatic plants are grown (Kruja 2020b). According to the Institute of Statistics (2020b), for the year 2019, around 40\% of the Albanian population is registered as a labour force working in the agriculture sector. Sustainability is critical in this sector as 'for local food producers requires a 
balance of supply (from producers) with demand (from consumers) in the face of volatile wealthier and prices' (Flora and Bregendahl 2012, p. 329). This makes the sector fragile in the need to continuously expand the market through product exporting to achieve economies of scale and increase its profits (Kruja 2020b).

This sector represents full integration possibilities into the supply chain and low-cost labour force. Due to its' favourable environmental conditions and opportunities of competitiveness in European markets, this sector embodies innovative, inclusive capacities in using digital platforms, peer-to-peer (P2P) collaboration, and developed collaboration on a larger scale, including main actors in the economy (industry-academiagovernment-society). However, despite that, there exist some disorders and a lack of regulations in this sector. Generally, this sector is composed of small-sized farms, which is rather difficult to include in a common collaborative structure. Additionally, there is a lack of a standard quality control system, which again poses some critical barriers. Collaboration is perceived as crucial for the enhancement of innovative processes, minimising the risk that entrepreneurs continuously face, especially for sustainable economic development (Kruja 2020b). The proper existence and a functional quadruple helix model that supports the collaborative economy in agriculture would serve to solve the identification of the clients, the identification of suitable trade networks, supply segments opportunities, and market price adjustments.

\section{Tourism Sector Vitality}

The tourism sector constitutes 26.2\% of Albania's GDP (World Travel \& Tourism Council 2018). Albania provides a variety of differentiated entertainment opportunities to tourists through mountain tourism, seaside tourism, historical tourism, and religious tourism. It is one of the main socio-economic resources of the country, contributing not only to job creation and employment but also to infrastructure and technological developments. The impact of technology in this sector has been a long-studied subject where researchers try to understand how technology shapes service processes and whether such enactment improves customer 
satisfaction and sector performance (Sari et al. 2006; Law et al. 2014; Melián-González and Bulchand-Gidumal 2016; Ferizi and Kruja 2018).

Collaborative economy in the tourism sector in Albania, as in other countries, is found to be highly vibrant and relatively competitive. This is due to a globally increased demand for tourism, especially for global tourism. In this context, the digital platforms (online applications allowing participants to interact with each other) are widely used by Albanians and foreigners, for example, Albania Tourism, Albania. al, Info Albania, Smile Albania, and Thema Tourism App. Yet, the tourism sector is characterised by two main sharing economic models, complementary to each other, which makes it quite interesting. The labour market in this sector is mainly short-term contracts or freelance work, otherwise defined as 'gig economy.' The other form of the economic model in tourism is the peer-to-peer economy, when the exchange of goods and services is directly concluded among two individuals, without the intermediation/intervention of a third party.

\section{Strengths, Weaknesses, Opportunities, and Threats Analysis}

This section is devoted to a general strengths, weaknesses, opportunities, and threats (SWOT) analysis evaluation for the Albanian case. As a first step, this study tries to find out the current situation of the agriculture and tourism sectors (given above) and then the main advantages and disadvantages that may arise in general. The best way to have a concrete framework of capacities, opportunities, and barriers is the SWOT analysis of both sectors.

Bakker and Twining-Ward (2018), in their study, have identified the top 10 opportunities and challenges of P2P accommodation from the literature. Accordingly, this study can highlight the selected features of this list of opportunities and challenges to be most evident in the case of Albania: Opportunities: (1) Helps attract new markets and demographics to new and existing destinations. Influences the type and nature of visitor purchases and services; (2) Builds consumer trust to visit a destination in new ways and try new products; (3) Lowers the barriers to entry for 
entrepreneurship; and (4) Increases access to market, which is particularly helpful for community-based homestays. Challenges cover: (1) Unregistered and unregulated P2P accommodation; (2) Not following tax laws; (3) P2P accommodation may cause housing prices and rents to increase; (4) May put visitors at higher risk; and (5) Providers lack organisation and representation.

As seen, the incorporation of sharing and collaborative aspects within this sector foresees significant progress and enhancement. On the other side, each of the challenges can be offset by a tight collaboration of main actors in the quadruple helix model. For instance, challenge 1, 2, and 4 can be improved by governmental intervention, which needs to be in frequent consultations with businesses, academia, and civil society. The collaboration among these actors should be an ongoing process that functions as a chain giving and getting the support of each other to improve as much as possible the sharing economy.

Figure 17.1 summarises the integrated SWOT analysis of both sectors considered in this study. The strengths are mainly related to the capacities of the existing young age structure and the readiness of academia to widely collaborate. At the same time, weaknesses are mainly related
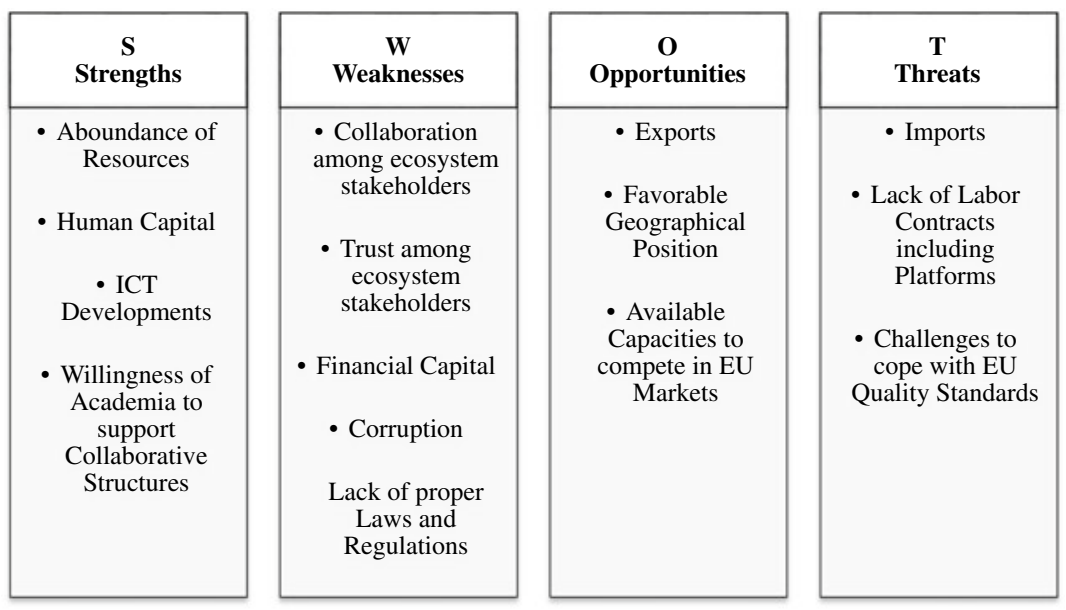

Fig. 17.1 Strengths, weaknesses, opportunities, and threats analysis of the main sharing economy sectors in Albania (Source Own elaboration) 
to the lack of appropriate policies to support sharing economy. Lastly, opportunities and threats are clear-cuts with each other, meaning that it depends on how they are managed and surpassed.

\section{Future Insights for a Solid Foundation of the Sharing Economy in Albania}

Accordingly, some suggestions are drawn based on the above-mentioned findings, which support as best as possible the concept of sharing economy. To be in line with the characteristics and features of the Albanian market structures, nature of domestic businesses, and businesses climate and environment, it is proposed the establishment of a solid framework of the 'quadruple helix model.' According to the EC's project 'ECORL Economy Co-responsibility Learning' (2016), online shopping, as one of the indicators related to sharing platforms, it is found to be not a common habit in Albania. Additionally, according to this project outcomes and suggestions, people in this country tend to rely too much on institutions to solve their problems. Inspired by the conclusions of this comparative study, it strongly advocates the collaboration of four main actors of the aforementioned model.

Even though Albania is starting to experience the effects of an ageing population, the Albanian population still represents a young population, having a median age of around 36 years. This is the reason Albania represents capacities to deal with internet usage, ICT development, digitalisation, and other relevant tools. Nevertheless, when analysing the spread of sharing economy and its' impact on the Albanian economy, a list of some existing obstacles and limitations might be obvious. As mentioned above, the sharing and collaborative concepts are still new to this market. This might be related to the lack of experience and market fragility. Parallel to this, another reason might be the unwillingness of businesses to collaborate with each other, inter-industry and intra-industry. Often, as a strategy to grow up, the observations show that the businesses in Albania decide to compete instead of collaborating. Apart from internal structures and decisions are taken by the companies, there are other external factors negatively affecting the sharing economy. 
The business environment in Albania is surely affected by the low performance of the sharing economy. As such, one of the external factors is the corruption level, which is relatively high compared to EU countries. Again, and still, important impeding factors to sharing economy is low trust and low reinforcement of laws and regulations. Moreover, the existence of problems with property rights and related issues might emerge as a fundamental obstacle for sharing and collaborative opportunities.

Universities, vocational education, and training (VET) entities, and institutes play a major role in the concept of sharing economy. They can be supporters with the platform conceptualisation and implementation, they can promote entrepreneurial spirit and foster ICT developments, and they can build bridges with the businesses to come up with solutions addressing the market needs. Development in sharing and collaborative economy can be achieved by having a smart combination of labour, capital, land, and entrepreneurship, with investment, exploration, education, and technology innovation (Berhani and Hysa 2013; Vladi and Hysa 2019).

Knowledge is the key element of the innovation systems, and the institutions which have an important role in its development can be stated as universities and academic institutions (develop and transfer knowledge), government organisations, and innovative enterprises (Kruja 2013). To achieve this knowledge in the form of sustainable innovation with an impact on sustainable development, the among and in-between industryacademia-government-society as defined by the 'quadruple helix model' is crucial. This collaboration model is an extension of Etzkowitz and Leydesdorff (1995) university-industry-government triple helix spiral collaboration, which recognised 'media-based and the culture-based public' as a fourth helix of collaboration by emphasising that 'culture and values, on the one hand, and the way how "public reality" is being constructed and communicated by the media, on the other hand, influence every national innovation system' (Carayannis and Campbell 2009, p. 206). Yun and Liu (2019) emphasise that the quadruple helix collaboration model is crucial for social, environmental, economic, cultural, policy, as well as knowledge sustainability necessary to bring about open innovation micro-dynamics and macro-dynamics. Through the synergic 
collaboration aiming at the advocacy and advancement of a sharing economy, the expected economic developments will be brought up.

Finally, there is an absence of transparent testimony of the quadruple helix support among industry-academia-government-society collaboration. Whenever sharing economy had been stimulated by the support of these actors' synergy, the sharing economy would have driven the economy forward through lower costs, increased consumer surplus, innovation, and exposure to larger markets. Figure 17.2 provides the framework for effective and efficient implementation of the collaborative economy for Albania, but not only. Through a synergic collaboration among the main economy's stakeholders, actors of the value co-creation process, the collaborative economy implementation will turn back to a sustainable development process to the country, enhancing its economic, social, and environmental improvement.

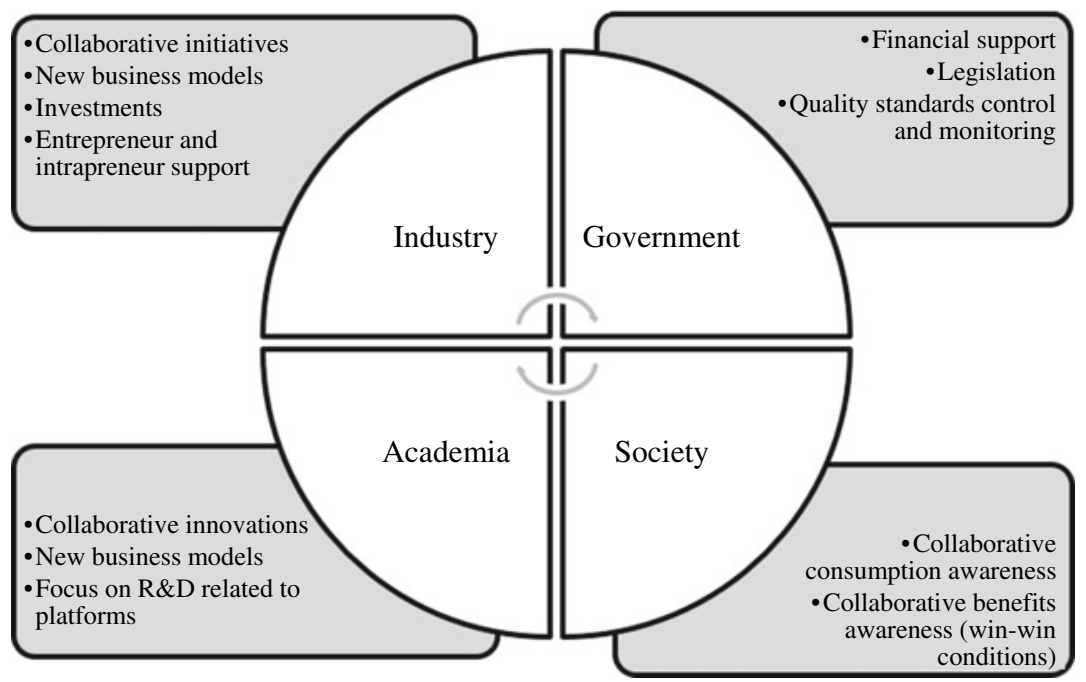

Fig. 17.2 Quadruple helix framework for the collaborative economy effectiveness (Source Own elaboration) 


\section{Discussion and Summary}

As one of the post-communist countries, Albania is yet considered a country in transition with respect to economic development and progress. The good news is that Albania is inspiring to join the EU in 2004, and thus, it aims to adopt the EU legislation and frameworks in regard to development. As the technology and innovation formulated policy are the right way to transform the economy into a knowledgebased economy (Alfaro et al. 2019), it can be said that this country has made some progress in adapting some strategies at the national level, which have in focus ICT development and digitalisation. Another positive aspect that helps in the adaption of technology and innovation is the young generation. Being keen on technology, the young generation promises to integrate novelties faster and further, which somehow can be considered as a very first step towards a collaborative or sharing economy.

Having a fragile economy, Albania is representing considerable limitations. First, there is a lack of common understanding of benefits and positive outcomes that might arise from a collaborative and sharing economy. The positive outcomes have to be considered at the micro-level and macro-level. The governmental bodies, non-governmental organisations (NGOs), and other relevant actors have to increase awareness and use the necessary channels to promote collaboration and sharing economy.

This research comes up with many contributions having crucial theoretical implications. First, the study acknowledged that the quadruple helix collaboration among industry-government-academia-society is the main facilitator and coordinator of the collaborative economy. The findings of the study encourage, at the same time, scholars to further research the impact of this collaboration on sharing economy enhancements, developments, and performance on other sectors as well as other developing and developed countries. Aside from the theoretical implications, this research points out also practical implications related to the ecosystem stakeholders— the quadruple helix actors: the government; the industry, the academia; and the society. The study findings highlight the necessity of collaboration among and in between the quadruple helix actors to achieve effective and efficient implementation of sharing 
economy. Albania, as a country with an abundance of natural resources, has a lot of capacities to serve not only domestic customers but also foreign customers of the agriculture and tourism sectors. These two sectors are decisive in the country's development as they both contribute almost to half of its gross domestic product (GDP). Through the sharing economy implementation, both sectors' entrepreneurs will be able to decrease operational costs, reduce unfair and unequal informality and competition, increase their markets, and better serve customers. For its accomplishment, it is requested a proper governmental policy planning for the sharing economy development; legislation; creating a proper infrastructural and technological support; subsidy and financial support for the sharing platforms developments. Along these lines, the Albanian government should put efforts into arranging the building and implementation of functional platforms and collaborative environments by creating the proper legislative framework in line with the EU directives and processes. Concurrent, academia and research institutions should intensify the urgent obligation of supporting these advancements. The contribution of academia in technological innovation and innovative business models support a vital part of this process. Finally, this process cannot be accomplished without society's support of collaborative consumption. An increase of awareness and trust on reciprocal benefits of $\mathrm{P} 2 \mathrm{P}$ consumption is decisive at this point. The continuous communication and synergic quadruple helix supportive collaboration of these stakeholders is necessary for the fragile and crucial sectors of the sharing economy's success in a developing country.

\section{References}

Alfaro, Emigdio, Fei Yu, Naqeeb Ur Rehman, Eglantina Hysa, and Patrice Kandolo Kabeya. 2019. 'Strategic Management of Innovation.' In The Routledge Companion to Innovation Management, edited by J. Chen, A. Brem, E. Viardot, and P. K. Wong, 107-168. UK: Routledge. 
Bakker, Martine, and Louise Twining-Ward. 2018. Tourism and the Sharing Economy: Policy and Potential of Sustainable Peer-to-Peer Accommodation. Washington, DC: World Bank.

Berhani, Riada, and Eglantina Hysa. 2013. 'The Economy of Albania Today and Then: The Drivers to Growth.' In The 4th International Conference on European Studies, 598. Albania: Epoka University.

Carayannis, Elias G., and David F. J. Campbell. 2009. "Mode 3" and "Quadruple Helix": Toward a 21st Century Fractal Innovation Ecosystem.' International Journal of Technology Management 46 (3-4): 201-234. https:// doi.org/10.1504/IJTM.2009.023374.

Corradini, Flavio, and Barbara Re. 2016. 'The European Digital Agenda and the Impact of ICT on Public Administrations and Small and Medium Enterprises.' In Proceedings of the 2nd International Conference on Recent Trends and Applications in Computer Science and Information Technology, Tirana, Albania, November 18-19, 2016. CEUR Workshop Proceedings 1746, CEUR-WS.org, pp. 11-16.

Council of Ministers. 2009. National Strategy of Science, 'Technology and Innovation 2009-2015.' Technical Report. Council of Ministers. The Republic of Albania. Accessed June 30, 2019. http://portal.unesco.org/en/files/47499/ 12677115709STI_english.pdf/STI\%2Benglish.pdf.

Economy Co-Responsibility Learning. 2016. 'Comparative Study on Sharing Economy in EU and ECORL Consortium Countries.' Technical Report. Economy Co-Responsibility Learning. Accessed June 30, 2019. https://www. ecorl.it/documenti/Risultati/comparative-study-on-sharing-economy.pdf.

Etzkowitz, Henry, and Loet Leydesdorff. 1995. 'The Triple Helix-UniversityIndustry-Government Relations: A Laboratory for Knowledge Based Economic Development.' EASST Review 14 (1): 14-19.

Ferizi, Vjosa, and Alba Demneri Kruja. 2018. 'Coastline Hospitality Industry Performance, Challenges, and Opportunities: Evidence from Durres Coastline.' In Managing Sustainable Tourism Resources, 14-38. Hershey, Pennsylvania: IGI Global. https://doi.org/10.4018/978-1-5225-5772-2.ch002.

Flora, Cornelia Butler, and Corene Bregendahl. 2012. 'Collaborative Community-Supported Agriculture: Balancing Community Capitals for Producers and Consumers.' International Journal of Sociology of Agriculture \& Food 19 (3): 329-346.

Gecaj, Merita, Edmira Ozuni Shahu, Drini Imami, Engjell Skreli, and Attila Jambor. 2019. Analysing the Impact of Subsidies in the Albanian Agriculture Sector: A Comparative Approach. Bulgarian Journal of Agricultural Science 25 (5): 883-890. https://doi.org/10.22004/ag.econ.271964. 
Hysa, Eglantina, and Egla Mansi. 2020. 'Integrating Teaching and Learning in Graduate Studies: Economic Development Course.' Technology Transfer: Innovative Solutions in Social Sciences and Humanities, 61-64. https://doi. org/10.21303/2613-5647.2020.001305.

Hysa, Eglantina, Alba Kruja, Naqeeb Ur Rehman, and Rafael Laurenti. 2020. 'Circular Economy Innovation and Environmental Sustainability Impact on Economic Growth: An Integrated Model for Sustainable Development.' Sustainability 12 (12). https://doi.org/10.3390/su12124831.

Hysa, Eglantina, Alba Demneri Kruja, and Vera Shiko. 2021. 'Current and Prospective Expansion of the Sharing Economy in Albania.' In The Collaborative Economy in Action: European Perspectives, edited by Andrzej Klimczuk, Vida Česnuitytè, and Gabriela Avram. Limerick, Ireland: University of Limerick.

Institute of Statistics. 2020a. 'Përdorimi i teknologjisë së informacionit dhe komunikimit në ndërmarrje, 2019 [Information and Communication Technology Usage in Enterprises, 2019].' Publication. Albanian Institute of Statistics. Accessed May 30, 2020. http://www.instat.gov.al/al/temat/ shkenc\%C3\%AB-teknologji-dhe-shoq\%C3\%ABria-dixhitale/informacionidhe-teknologjit\%C3\%AB-e-komunikimit/publikimet/2020/teknologjia-einformacionit-dhe-komunikimit-n\%C3\%AB-nd\%C3\%ABrmarrje-2019/.

Institute of Statistics. 2020b. Sectorial Based Labor Force 2000-2019. Accessed July 28, 2020. Retrieved from http://databaza.instat.gov.al/pxweb/sq/DST/ START_TP_AD_ADY/ADY132/table/tableViewLayout $2 /$ ? rxid $=2 \mathrm{~d} 5$ 82861-bfe1-4141-a7e6-5d95288cbf60.

International Telecommunication Union. 2016. 'ICT Centric Innovation Ecosystem Country Review: Albania.' Technical Report. Accessed on June 30, 2019. https://www.itu.int/en/ITU-D/Innovation/Documents/Publications/ Albania\%20Country\%20Review\%20Innovation\%20June\%202016.pdf.

Kemp, S. 2020. 'Digital 2020. Report.' Hootsuite. Accessed May 30, 2020. https://hootsuite.com/resources/digital-2020.

Kruja, Alba. 2013. 'Entrepreneurship and Knowledge-Based Economies.' Revista Românească pentru Educaţie Multidimensională 1: 7-17.

Kruja, Alba. 2020a. 'Entrepreneurial Orientation, Synergy and Firm Performance in the Agribusiness Context: An Emerging Market Economy Perspective.' Central European Business Review 9 (1): 56-75. https://doi.org/10. 18267/j.cebr.229.

Kruja, Alba Demneri. 2020b. 'Entrepreneurial Challenges of Albanian Agribusinesses: A Content Analysis.' JEEMS Journal of East European 
Management Studies 25 (3): 530-554. https://doi.org/10.5771/0949-61812020-3-530.

Law, Rob, Dimitrios Buhalis, and Cihan Cobanoglu. 2014, 'Progress on Information and Communication Technologies in Hospitality and Tourism.' International Journal of Contemporary Hospitality Management 26 (5): 727750. https://doi.org/10.1108/IJCHM-08-2013-0367.

Melián-González, Santiago, and Jacques Bulchand-Gidumal. 2016. 'A Model That Connects Information Technology and Hotel Performance.' Tourism Management 53: 30-37. https://doi.org/10.1016/j.tourman.2015.09.005.

Ministry of Innovation and Public Administration. 2014. 'Cross-Cutting Strategy: Digital Agenda of Albania 2015-2020.' Technical Report. Ministry of Innovation and Public Administration. Republic of Albania. Accessed June 30, 2019. https://akshi.gov.al/wp-content/uploads/2018/03/Digital_A genda_Strategy_2015_-_2020.pdf.

Sari, Yasar, Metin Kozak, and Teoman Duman. 2006. 'A Historical Development of "IT" in Tourism Marketing.' In Progress in Tourism Marketing, edited by M. Kozak and L. Andreu, 33-44. Netherlands: Elsevier.

Stahel, Walter. 2010. The Performance Economy. Basingstoke, UK: Palgrave Macmillan.

TIMBRO. 2018. 'Sharing Economy Index.' Technical Report. TIMBRO. Accessed June 30, 2019. https://timbro.se/app/uploads/2018/07/tsei-ver sion-17_web.pdf.

Tukiainen, Taina, Seppo Leminen, and Mika Westerlund. 2015. 'Cities as Collaborative Innovation Platforms.' Technology Innovation Management Review 5 (10): 16-23. https://doi.org/10.22215/TIMREVIEW/933.

Vladi, Eneda, and Eglantina Hysa. 2019. 'The Impact of Macroeconomic Indicators on Unemployment Rate: Western Balkan Countries.' In International Firms' Economic Nationalism and Trade Policies in the Globalisation Era, edited by Harish C. Chandan and Bryan Christiansen, 158-181. Hershey, Pennsylvania: IGI Global.

World Travel \& Tourism Council. 2018. 'Travel \& Tourism Economic Impact 2018: Albania.' World Travel \& Tourism Council, United Kingdom.

Wosskow, Debbie. 2014. Unlocking the Sharing Economy: An Independent Review. London: Department for Business, Innovation and Skills. Accessed June 30, 2019. Retrieved from https://www.gov.uk/government/uploads/sys tem/uploads/attachment_data/file/378291/bis-14-1227-unlocking-thesha ring-economy-an-independent-review.pdf. 
Yun, JinHyo Joseph, and Zheng Liu. 2019. 'Micro-and Macro-Dynamics of Open Innovation with a Quadruple-Helix Model.' Sustainability 11 (12): 3301. https://doi.org/10.3390/su11123301.

\section{Suggested Readings}

Čavalić, Admir. 2017. Sharing Economy in Western Balkans: Potential for Rural Development. Bosnia and Hercegovina: International Burch University.

Duli, Manjola. 2019. Albania: Report on the Preparation of Post-2020 Strategy. Bosnia and Hercegovina: Regional Cooperation Council.

Kruja, Alba Demneri, and Geri Ruci. 2021. 'Sharing Economy Perspectives for a Sustainable Agriculture and Tourism Development.' In International Scientific Conference 'Sustainable Agriculture and Rural Development, Institute of Agricultural Economics, Belgrade, December 17-18, 2020, Belgrade, Serbia.

OECD. 2020. OECD Tourism Trends and Policies 2020. Paris: OECD Publishing. https://doi.org/10.1787/6b47b985-en.

\section{Relevant Websites}

Agroquality: http://agroquality.al/?lang=en/.

Digital technologies key to accelerate agricultural development in Albania, United Nations Albania: https://albania.un.org/en/104824-digital-techno logies-key-accelerate-agricultural-development-albania.

Innovation Map Albania: https://innovationmapalbania.org/about. 
Open Access This chapter is licensed under the terms of the Creative Commons Attribution 4.0 International License (http://creativecommons.org/ licenses/by/4.0/), which permits use, sharing, adaptation, distribution and reproduction in any medium or format, as long as you give appropriate credit to the original author(s) and the source, provide a link to the Creative Commons license and indicate if changes were made.

The images or other third party material in this chapter are included in the chapter's Creative Commons license, unless indicated otherwise in a credit line to the material. If material is not included in the chapter's Creative Commons license and your intended use is not permitted by statutory regulation or exceeds the permitted use, you will need to obtain permission directly from the copyright holder.

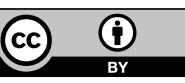

